\title{
Microstructural characterisation of five simulated archaeological copper alloys using light microscopy, scanning electron microscopy, energy dispersive X-ray microanalysis and secondary ion mass spectrometry ${ }^{\text {负 }}$
}

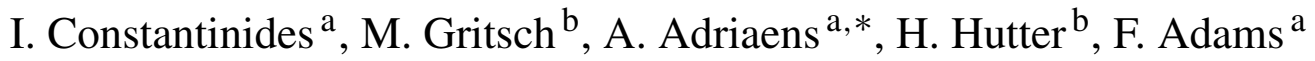 \\ a Department of Chemistry, University of Antwerp, Universiteitsplein 1, 2610 Wilrijk, Belgium \\ ${ }^{\mathrm{b}}$ Institute of Analytical Chemistry, Technical University of Vienna, Getreidemarkt 9/151, 1060 Wien, Austria
}

Received 31 October 2000; received in revised form 6 April 2001; accepted 18 April 2001

\begin{abstract}
This paper describes the microstructural characterisation of five simulated archaeological copper alloys, produced by modern powder technology. The chemical composition of the examined bronzes covers the major families of archaeological bronzes from antiquity until the Roman period. Light microscopy (LM), energy dispersive X-ray microanalysis (EDX), scanning electron microscopy (SEM) as well as two- and three-dimensional secondary ion mass spectrometry (SIMS) have been used to describe the main properties of the alloys. The results show a heterogeneous microstructure on a micrometer scale, formed by metallic and non-metallic phases. The latter are conglomerates of oxides or sulphides of major or minor elements. (C) 2001 Elsevier Science B.V. All rights reserved.
\end{abstract}

Keywords: Microanalysis; Copper alloys; Certified reference materials; Archaeometry; SEM-EDX; 2-3D SIMS; Light microscopy

\section{Introduction}

It is well-known that bronze melts of the same chemical bulk composition may form alloys with a widely different microstructure. Depending on the process parameters, the composition of the mixed crystals will vary and the size and geometrical distribution of

\footnotetext{
The work forms part of the Improvement of Means of Measurements on Archaeological Copper Alloys for Characterisation and Conservation Project (IMMACO), which fits within the Standards, Measurement and Testing (SM\&T) Program of the European Union DG XII (contract no. SMT4CT96-2055, 1997-2000).

* Corresponding author. Tel.: +32-38202340; fax: $+32-38202376$.

E-mail address: mieke.adriaens@ua.ac.be (A. Adriaens).
}

the microphases may show large differences. The samples in this work were produced using a hot isostatic pressing (HIP) technique. This method has proven to be a good approach for making alloys, as it leads in general to higher micro- and macroscopic homogeneity [1]. The five bronzes in this study have a composition that is representative for the major copper alloys known in antiquity. They are a quaternary bronze, an arsenical copper, a tin bronze, a lead bronze and a brass. Their nominal composition is listed in Table 1.

The compositions were certified in a separate study for the mass fractions of the main alloying elements $\mathrm{As}, \mathrm{Sn}, \mathrm{Pb}$ and $\mathrm{Zn}$ [2]. The intended application for the certified alloys is the calibration of energy dispersive X-ray fluorescence (XRF) spectrometers, which 
Table 1

Overview of candidate reference materials ${ }^{\mathrm{a}}$

\begin{tabular}{|c|c|c|c|c|c|}
\hline Elements & Quaternary bronze (1) & Arsenical copper (2) & Tin bronze $(3)$ & Lead bronze (4) & Brass (5) \\
\hline \multicolumn{6}{|c|}{$\mathrm{Cu}$ (main composition) } \\
\hline Sn & 7.00 & 0.20 & 7.00 & 10.00 & 2.00 \\
\hline $\mathbf{P b}$ & 9.00 & 0.20 & 0.20 & 10.00 & 0.40 \\
\hline As & 0.20 & 5.00 & 0.20 & 0.30 & 0.10 \\
\hline $\mathbf{Z n}$ & 6.00 & - & 0.10 & 0.10 & 15.00 \\
\hline $\mathrm{Fe}$ & 0.20 & 0.20 & 0.30 & 0.10 & 0.50 \\
\hline $\mathrm{Mn}$ & 0.20 & 0.20 & 0.30 & 0.10 & 0.40 \\
\hline $\mathrm{Ni}$ & 0.10 & - & 0.50 & 0.30 & 0.20 \\
\hline $\mathrm{S}$ & 0.30 & 0.30 & 0.50 & - & 0.30 \\
\hline $\mathrm{Sb}$ & 0.50 & 0.50 & 0.70 & 0.30 & - \\
\hline
\end{tabular}

${ }^{a}$ Mass fractions in percentage. The elements in bold have been certified [2]. Composition numbers are shown in parentheses.

is the preferred method for non-destructive analysis of archaeological bronzes, particularly in the field [3]. The fact that the samples are simulated archaeological copper alloys makes them unique as reference materials. In addition, a separate guide for "good analytical practice" for the study of bronze artifacts by XRF spectrometry has been made available and covers in detail aspects of the analysis method, detection limits and quantification procedures [4]. It will allow the acquisition of more reliable data on ancient copper alloy compositions.

When establishing reference materials for XRF spectrometry, a microstructural characterisation of each material is necessary, since matrix effects are different depending on the local chemical composition of the target and will influence the absorption of the generated X-rays. This paper will therefore, focus on the microstructural characterisation of the five bronze materials using light microscopy (LM), scanning electron microscopy with energy dispersive $\mathrm{X}$-ray analysis (SEM-EDX) and secondary ion mass spectrometry (SIMS). A detailed study concerning the homogeneity of the material on the millimetre scale, which may limit the precision and accuracy for XRF analyses, was performed in a separate study [2].

LM will allow a rapid and representative characterisation of the microstructure in terms of the classical metallographic description of an alloy. Information on the size of the phases and their distribution across their micrometer domains will be obtained from large and representative areas of the specimen [5]. SEM-EDX will be used for imaging the phase distributions with back-scattered electrons (BSEs) and for the quantitative microanalysis of individual phases. The technique will allow an excellent discrimination of microphases with a different chemical composition, thus, yielding an assignment of the microstructure features to the various chemical phases formed (e.g. alpha-phase, delta-phase, gamma-mixed crystals). Such a quantitative microanalysis can be performed with an accuracy of 1-5\% for major and minor constitutions. SIMS will be used for a qualitative characterisation of the distribution of trace elements, such as arsenic. Two- and three-dimensional characterisation of these elements will be performed. The goal is to determine whether these trace elements are locally precipitated or dissolved in the matrix, as they may have a substantial influence on the corrosion behaviour of the alloy [6,7].

\section{Experimental}

\subsection{Production process}

The alloys were prepared at the Institute of Reference Materials and Measurements (IRMM), Geel, Belgium, using a powder metallurgy technique. Elemental powders with a purity of $99 \%$ or higher, and a mesh size of $100(150 \mu \mathrm{m})$ were used [2]. All components were mechanically blended and, in a second step, were sieved to break down agglomerated particles. A cold isostatic pressing (CIP) process was performed under 1500 bar in a "wet bag" to produce compacts of about $90 \%$ density. The compact was then vacuum-sealed 
in stainless steel and underwent a HIP procedure $\left(1000\right.$ bar at $820^{\circ} \mathrm{C}$ during $\left.2 \mathrm{~h}\right)$. The HIP treatment involves the simultaneous application of heat and pressure of cast materials to improve the uniformity of the cast. The pressure medium is usually an inert gas, in this case Ar. The obtained HIPped billets were unwrapped by removal of the stainless steel jackets.

This three-step procedure was used to produce 47 billets of the candidate certified reference materials (CRMs), each $200 \mathrm{~mm}$ long and $45 \mathrm{~mm}$ in diameter. The billets were reduced to $35 \mathrm{~mm}$ in diameter with a turning lathe and cut into slices using a $\mathrm{SiC}$ cutting wheel. Finally, discs of $2 \mathrm{~mm}$ thickness were sliced to obtain the shape for analysing. For the SIMS measurements, special discs of $25 \mathrm{~mm}$ in diameter and of $5 \mathrm{~mm}$ thickness were produced in order to be able to fit into the SIMS sample holder.

\subsection{Analytical approach}

The samples were ground mechanically using SiC grinding paper, covering a grain size from 180 to $4000 \mathrm{mesh} / \mathrm{in}$. Afterwards, a polishing step followed with a cloth and diamond spray up to $1 \mu \mathrm{m}$. In some cases, it was necessary to smooth the edges of remaining scratches using an oxide polishing type $\mathrm{U}$ (universal) (OP-U) suspension of $\mathrm{SiO}_{2}$ (StruesDivision, France). As a result, fewer shadow effects occurred on the sample surface. For SIMS analyses, the samples were additionally rinsed in an ultrasonic bath with ethanol for $15 \mathrm{~min}$.

Although numerous sophisticated metallographic tools are available, LM allows a rapid and representative characterisation of the microstructure to be obtained in terms of the classical metallographic description of an alloy. Particular attention is paid to the determination of the structural phases and the constitution of the bulk, which represent in fact the whole physical makeup of the material and have a strong influence on the behaviour of the material. The metallographic images were taken with a Reichert MeF3A (Vienna) light microscope and an Olympus SZX-12 LM (Hamburg, Germany) [8,9]. All samples were examined unetched using unpolarised and plane polarised light with magnifications ranging from 100 to $500 \times$.

SEM-EDX measurements were performed to analyse for major and minor elements both qualitatively and quantitatively. A Jeol 6300 scanning electron microscope (Mitaka, Japan) was used, equipped with an ED-XRF $\mathrm{Si}(\mathrm{Li})$ detection system. The following instrumentation settings were used: $20 \mathrm{kV}$ acceleration voltage, $1 \mathrm{nA}$ beam current, $150 \mathrm{~s}$ analysis time and a working distance of $19 \mathrm{~mm}$. If not stated otherwise, a magnification setting of about $100 \times$ was chosen corresponding to an area of analysis of about $1200 \mu \mathrm{m} \times 1100 \mu \mathrm{m}$ for the bulk analysis. The net elemental X-ray intensities were calculated with the program analysis of X-rays by iterative least squares (AXIL) and a standardless ZAF program was used to calculate the compositions [10-12]. Various reference materials of the National Institute of Standards and Technology (NIST) were used to validate the quantification procedure.

SIMS measurements were performed using a modified Cameca IMS 3f/4f instrument (Courbevoie, France). An $\mathrm{O}_{2}{ }^{+}$primary ion beam with an impact energy of $5.5 \mathrm{kV}$ and a beam current of $1.5 \mu \mathrm{A}$ was scanned over an area of $300 \mu \mathrm{m} \times 300 \mu \mathrm{m}$ to illuminate the analysed area homogeneously. Positive secondary ions were detected from an analysed area of $150 \mu \mathrm{m}$ in diameter and were accelerated into a double-focusing mass spectrometer by an accelerating voltage of $+4.5 \mathrm{kV}$. For the image acquisition, the mass separated positive secondary ions were projected onto a dual micro-channel plate.

The imaging system consisted of a sensitive (0.02 lux) standard charged-coupled device (CCD) camera attached to the double micro-channel plate fluorescent assembly (Galileo High Output Technology, HOT). The camera signal was digitised by a frame-grabber PC card (Matrox Pulsar) and stored on the hard disc of the controlling computer. Adding up 256 images of the 8-bit analog-to-digital conversion provided 256 pixel $\times 256$ frames with 16 -bit digital resolution. Furthermore, a fully PC controlled automatic adjustment of the channel plate high voltage (cphv) was of importance to avoid the channel plate being destroyed, if the signal becomes too strong $[13,14]$. However, the cphv had to be augmented in case of decreasing signals to keep on track also with small inclusions. Therefore, the cphv must be adjusted dynamically during a 3D measurement as secondary ion intensities changed in order to stay within a linear range of the channel plate. Parallel to the acquisition of the images, an electron multiplier signal was 
recorded, resulting in a "conventional" depth profile. Single images were stored in a directory together with the 1D depth profile that contained the measured element/s and cycle number, integral counts from the electron multiplier, the cphv as well as the number of frames. Afterwards, post-processing software rebuilt the 3D distribution. The program VisualSIMS, developed by the Vienna group, allowed piling up single images data, which could be visualised from arbitrary views of angle $[15,16]$.

\section{Results and discussion}

\subsection{The quaternary bronze}

Optical examinations of the quaternary bronze $(\mathrm{Cu}-\mathrm{Sn}-\mathrm{Zn}-\mathrm{Pb}$ alloy) were performed revealing a heterogeneous microstructure. Two main phases were distinguished: a metallic $\alpha$-phase and a non-metallic phase, consisting of conglomerates of different inclusions. The metallic phase clearly shows the presence of annealing twins indicating a change from one crystal structure to another during recrystallisation. The sintering process, however, was not sufficient to eliminate the oxide layer and consequently the presence of the remaining powder particles at the grain boundaries of the metallic phase. The various non-metallic phases are visible in different shades of grey under unpolarised light (Fig. 1). In plane-polarised light, the areas become coloured and compounds, such as $\mathrm{CuS}$ appear light-blue while orange to yellow inclusions represent $\mathrm{CuO}$ (Fig. 2). In between the $\mathrm{CuS}$ and $\mathrm{CuO}$ inclusions those of $\mathrm{PbO}$ are situated, which appear also bluish like the $\mathrm{CuS}$ (see arrows in (Fig. 1). The inclusions are spread over the entire sample surface and are either present as separate inclusions or as conglomerates. Their size varies between 20 and $150 \mu \mathrm{m}$. Usually, oxides and sulphides can be found together.

Fig. 3 shows a backscattered electron (BSE) image of the quaternary bronze (QB). Energy dispersive X-ray measurements were made at several sample positions to obtain a quantitative overview of the sample composition (Table 2). The specific labels in Table 2 are assigned according to the grey scale seen in the BSE images. The results of the analyses can be summarised as follows: a metallic $\alpha$-phase consisting mainly of $\mathrm{Cu}(86 \%)$ and $\mathrm{Sn}(11 \%)$ with a small

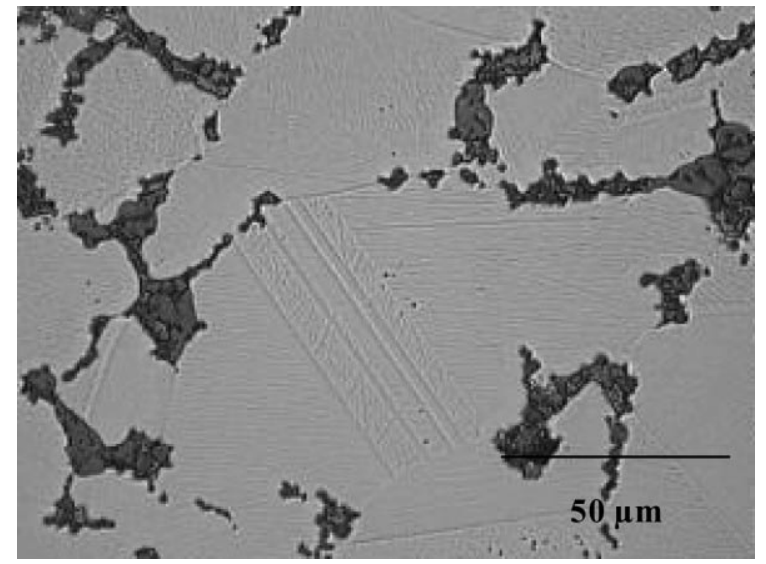

Fig. 1. Light microscopy image of the quaternary bronze showing a typical distribution of the different inclusions. The grain boundary is formed by oxidised powder particles. Furthermore, annealing twins are visible indicating the recrystallisation of grains during the production process (magnification $400 \times$ ).

percentage of $\mathrm{Zn}(<3 \%)$; the 'bright inclusions' are immiscible $\mathrm{PbO}$; the 'dark-grey inclusions' are $\mathrm{ZnS}$ with small amounts of $\mathrm{CuS}$; the 'black inclusions' contain $\mathrm{CuS} / \mathrm{ZnS}$ together with minor elements, such as $\mathrm{As}, \mathrm{Fe}, \mathrm{Ni}, \mathrm{Mn}$ and $\mathrm{Sb}$. These results confirm the results Munnik et al. [17].

In Fig. $4 \mathrm{a}$ and $\mathrm{b}$, the results obtained by SIMS measurements are summarised. The distributions of the

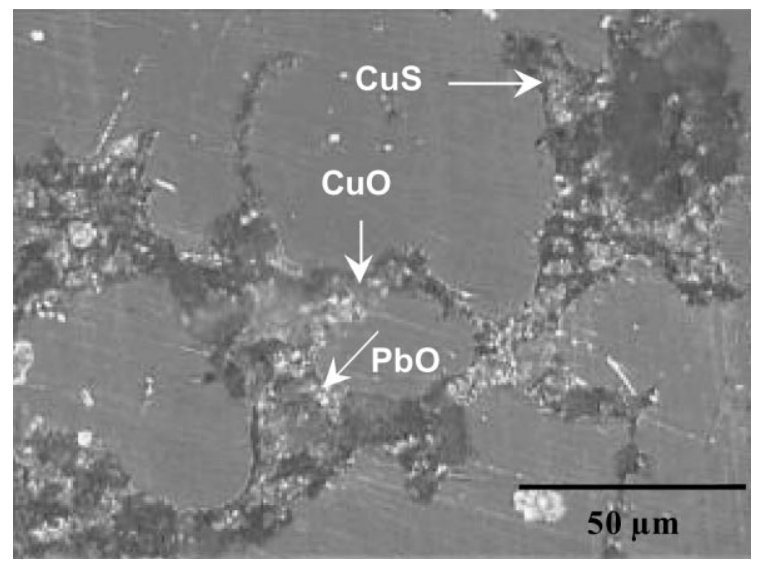

Fig. 2. Light microscopy image of the quaternary bronze under polarised light. Large areas of $\mathrm{CuS}$ appear light-blue while the orange-yellow inclusions are $\mathrm{CuO}$. In between the $\mathrm{CuS}$ and $\mathrm{CuO}$ inclusion those of $\mathrm{PbO}$ are situated having a similar light-bluish colour (magnification $400 \times$ ). 


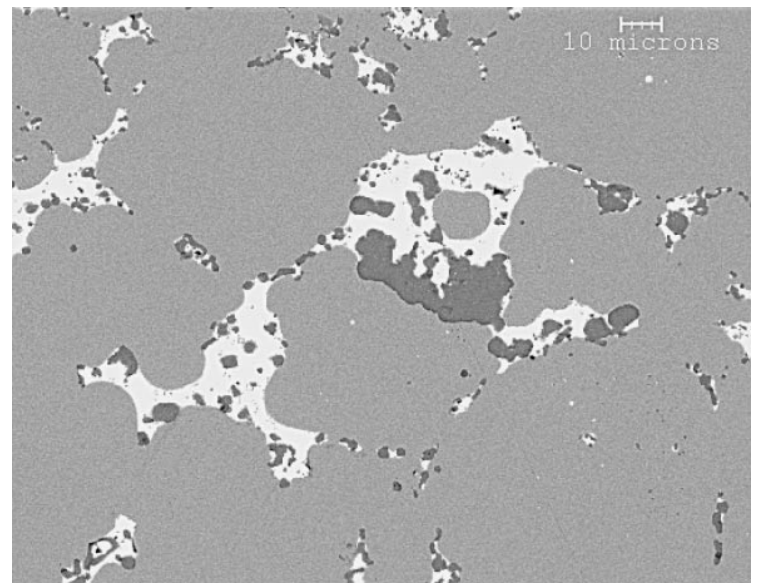

Fig. 3. Backscattered electron (BSE) image of the quaternary bronze. The bright areas belong to immiscible lead oxide. All other grey shades, dark-grey or even black, are areas or inclusions of different oxide and sulphide inclusions (magnification $650 \times$ ).

elements are presented in a block view, in which every colour pixel on the surface is related to the count rate (c/s) at this location. The images are scaled individually so that the maximum contrast is visible. Results show that the $\alpha$-phase-forming elements $\mathrm{Cu}$ and $\mathrm{Sn}$ are only partially homogeneously distributed, clearly showing enriched areas. $\mathrm{Pb}$ is found in the outer part of the analysed area and reveals a few enriched regions at the rim of the block. $\mathrm{Zn}$ is located mainly in inclusions at the grain boundaries of the $\alpha$-phase, whereby some of them reach approximately $3 \mu \mathrm{m}$ in depth. Minor elements such as Fe, Mn and $\mathrm{Sb}$ are found at the same locations as $\mathrm{Zn}$. The corresponding 3D blocks of these elements show a mottled pattern, which is a result of the elongated powder particles. The size of these particles varies from 3 to $70 \mu \mathrm{m}$.

\subsection{The arsenical copper}

The arsenical copper $(\mathrm{Cu}-\mathrm{As}$ alloy) again shows the presence of a metallic and a non-metallic phase. The non-metallic phase consists of various types of inclusions, such as 'dark inclusions' of CuS; 'black inclusions' consisting of several elements, such as $\mathrm{Cu}, \mathrm{As}, \mathrm{Mn}, \mathrm{Fe}, \mathrm{Sb}$ in combination with $\mathrm{S}$; 'bright inclusions' containing Sn with low amounts of $\mathrm{Cu}$ and As $(<3 \%)$ (Fig. 5). They range in size from 5 to $50 \mu \mathrm{m}$ for the smaller and $>50$ to $200 \mu \mathrm{m}$ for the larger ones. They show a clear difference in their consistency, i.e. some inclusions are dense while others have a higher porosity. Next to the metallic $\alpha$-phase, consisting of $3 \%$ As, the alloy reveals the intermetallic compound $\mathrm{Cu}_{3}$ As, with As concentrations up to $28 \%$ (Fig. 6).

The results of the 3D SIMS images are illustrated in Fig. 7. A heterogeneous distribution for $\mathrm{Cu}$ and $\mathrm{As}$ is observed. The circled inclusion, e.g. raises approximately $7 \mu \mathrm{m}$ in depth and stops suddenly indicating local variations in the As concentration. Sn can be visualised only as a single spot here. $\mathrm{Pb}$ is present in trace amounts and forms an immiscible phase of small globules varying between 3 and $9 \mu \mathrm{m}$ in size.

Table 2

Average composition in wt.\% of the two main phases of the QB (mean \pm S.D.) ${ }^{\mathrm{a}}$

\begin{tabular}{|c|c|c|c|c|}
\hline \multirow[t]{2}{*}{ Element } & \multirow{2}{*}{$\begin{array}{l}\text { Metallic phase } \\
\alpha \text {-Phase }\end{array}$} & \multicolumn{3}{|l|}{ Non-metallic phase } \\
\hline & & Bright inclusion $^{\mathrm{b}}$ & Dark-grey inclusion & Black inclusion \\
\hline$\overline{\mathrm{Cu}}$ & $86.0 \pm 0.5$ & $2.5 \pm 0.3$ & $4.0 \pm 0.4$ & $35 \pm 1$ \\
\hline $\mathrm{Sn}$ & $10.5 \pm 0.3$ & $0.6 \pm 0.1$ & $0.9 \pm 0.2$ & $5.3 \pm 0.1$ \\
\hline $\mathrm{Pb}$ & N.D. & $96 \pm 2$ & N.D. & N.D. \\
\hline $\mathrm{Zn}$ & $2.8 \pm 0.3$ & $0.7 \pm 0.2$ & $71.0 \pm 0.5$ & $48 \pm 8$ \\
\hline $\mathrm{Fe}$ & $0.20 \pm 0.01$ & $0.3 \pm 0.2$ & $0.5 \pm 0.2$ & $1.6 \pm 0.2$ \\
\hline Mn & $0.40 \pm 0.06$ & N.D. & $0.20 \pm 0.01$ & $1.4 \pm 0.3$ \\
\hline $\mathrm{Ni}$ & $0.20 \pm 0.01$ & N.D. & N.D. & $0.30 \pm 0.01$ \\
\hline As & N.D. & N.D. & $0.30 \pm 0.01$ & $0.4 \pm 0.1$ \\
\hline $\mathrm{Sb}$ & $0.3 \pm 0.1$ & $0.3 \pm 0.1$ & $0.5 \pm 0.1$ & $0.5 \pm 0.2$ \\
\hline $\mathrm{S}$ & N.D. & N.D. & $23 \pm 1$ & $7.0 \pm 1.3$ \\
\hline
\end{tabular}

\footnotetext{
a Standard deviation, $n=3$.
}

${ }^{\mathrm{b}} \mathrm{Pb}$ is present as $\mathrm{PbO}$ and therefore, assigned to the non-metallic phase; N.D.: not detected. 


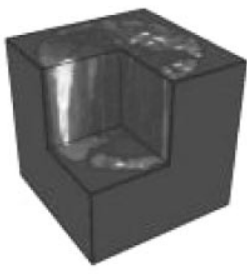

Cu block

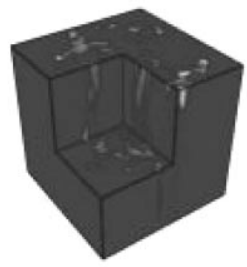

(a)

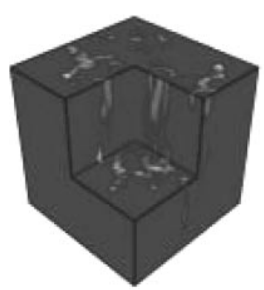

Fe block

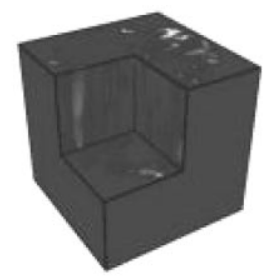

Sn block

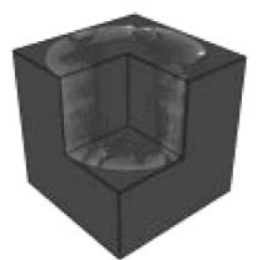

$\mathrm{Pb}$ block

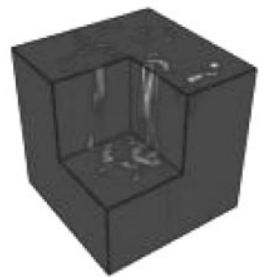

Mn block (b)

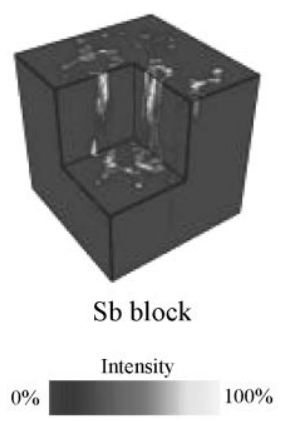

Fig. 4. ( $a$ and b) SIMS 3D distribution of the major and minor elements in the quaternary bronze, presented in a "block" view. The block has a size of $(x, y)=150 \mu \mathrm{m}$ and $z=10 \mu \mathrm{m}$.

\subsection{The tin bronze}

The tin bronze $(\mathrm{Cu}-\mathrm{Sn}$ alloy) shows an irregular metallic grain structure interspersed by large non-metallic inclusions. The size of these inclusions ranges from 1 up to $120 \mu \mathrm{m}$. They can be divided into three types (Fig. 8): 'dark-grey inclusions'

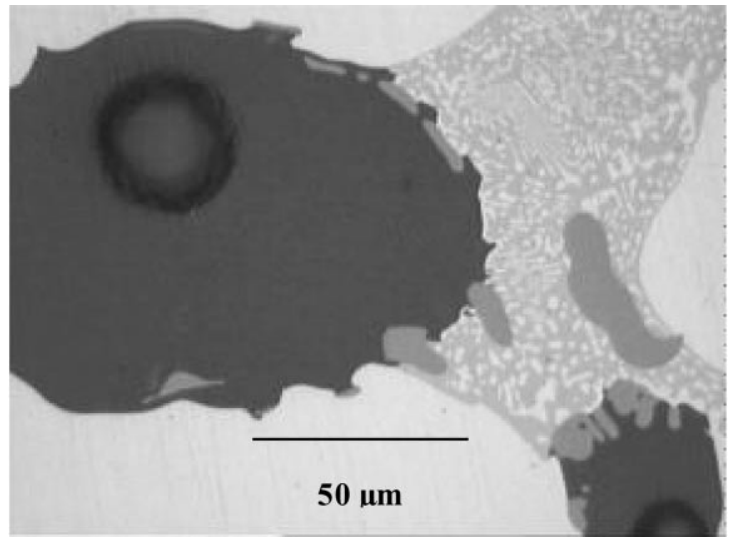

Fig. 5. Backscattered electron image of the arsenical copper. The $\alpha$-phase consists of $\mathrm{Cu}$ and As. The dark-grey areas are $\mathrm{CuS}$ and the black regions are $\mathrm{CuS}, \mathrm{MnS}, \mathrm{FeS}, \mathrm{SbS}$ and $\mathrm{As}_{n} \mathrm{~S}_{m}$. Pure $\mathrm{Sn}$ is situated in the bright inclusions (magnification $300 \times$ ).

composed of $\mathrm{Sn}$ and $\mathrm{Mn}$ together with $\mathrm{Fe}$ and $\mathrm{Zn}$ as sulphides, 'bright inclusions' containing $\mathrm{Sn}$ as oxides and sulphides with some $\mathrm{Cu}$ and $\mathrm{Pb}$ and the "black inclusions' are mainly $\mathrm{CuS}$ with $\mathrm{Mn}, \mathrm{Fe}, \mathrm{Ni}, \mathrm{Zn}$ and $\mathrm{Sb}$ all having concentrations of $<0.5 \%$. The metallic phase is an $\alpha$-phase and is composed of $90 \% \mathrm{Cu}$ and $8 \% \mathrm{Sn}$, with minor amounts of $\mathrm{Sb}$ and $\mathrm{Ni}(<1 \%)$.

SIMS images show a 2D distribution of the major $(\mathrm{Cu}$ and $\mathrm{Sn})$ as well as the minor ( $\mathrm{Mn}$ and $\mathrm{Fe}$ ) elements demonstrating the heterogeneity within an area of diameter $150 \mu \mathrm{m}$ (Fig. 9).

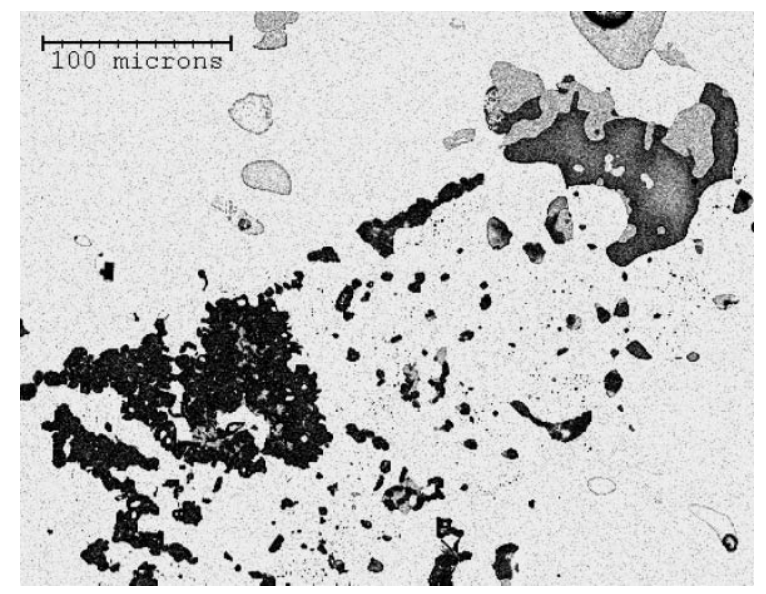

Fig. 6. Light microscopy image of the As-bronze with the intermetallic compound $\mathrm{Cu}_{3}$ As (magnification $400 \times$ ). 
Cu block

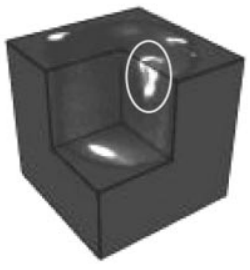

As block

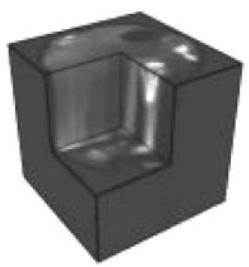

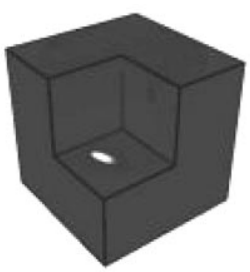

Sn block

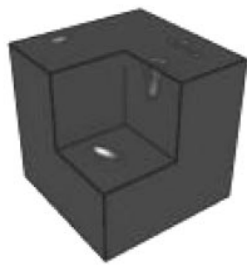

$\mathrm{Pb}$ block

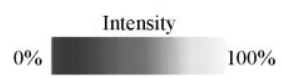

Fig. 7. SIMS $3 \mathrm{D}$ distribution of the elements $\mathrm{Cu}, \mathrm{Sn}, \mathrm{As}$ and $\mathrm{Pb}$ in the arsenical copper.

\subsection{The lead bronze}

Also for the lead bronze ( $\mathrm{Cu}-\mathrm{Sn}-\mathrm{Pb}$ alloy), $\mathrm{LM}$ investigations show a heterogeneous structure. A metallic and a non-metallic phase can be observed. Fig. 10 shows a typical BSE image. The metallic

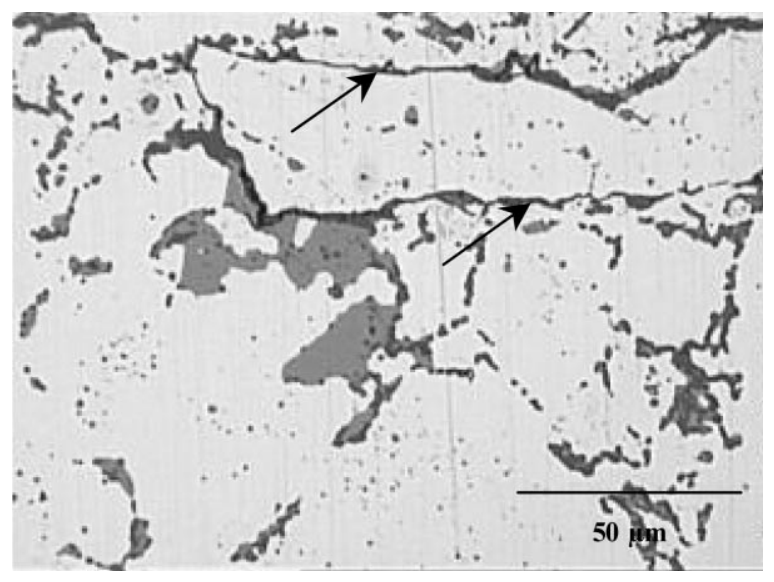

Fig. 8. Deformed powder grains, visible in long thin dark-grey lines taken under plane-polarised light. The elongated inclusions are $\mathrm{CuS}$ (magnification $400 \times$ ).

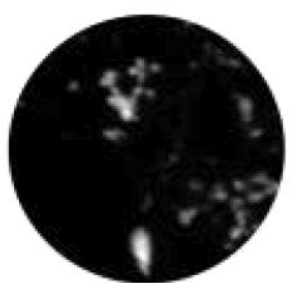

$55 \mathrm{Mn}$

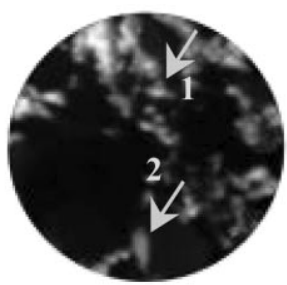

$120 \mathrm{Sn}$

Intensity

$0 \%$

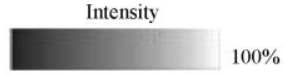

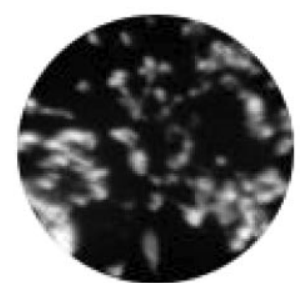

$56 \mathrm{Fe}$

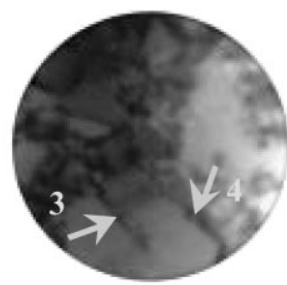

$63 \mathrm{Cu}$

$\varnothing 150 \mu \mathrm{m}$
Fig. 9. SIMS 2D distribution of the elements $\mathrm{Mn}, \mathrm{Fe} \mathrm{Sn}$ and $\mathrm{Cu}$ in the tin bronze.

$\alpha$-phase consists of $\mathrm{Cu}(88 \%)$ and $\mathrm{Sn}(11 \%)$, with small amounts of $\mathrm{Ni}$ and $\mathrm{Pb}$ (both $\sim 0.5 \%$ ). Large bright inclusions originate from pure $\mathrm{Pb}$ globules and partly from $\mathrm{Cu}$ and $\mathrm{PbO}$. This can be easily distinguished in LM analyses by changing the illumination

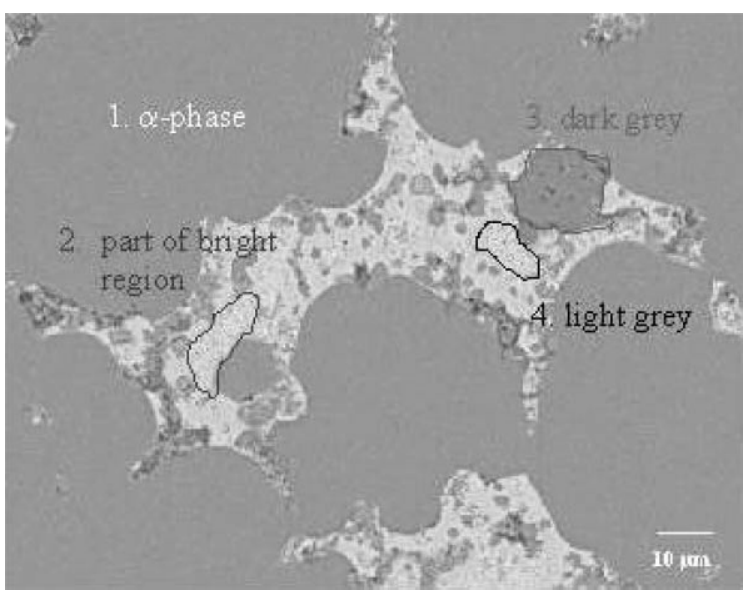

Fig. 10. Backscattered electron image of the lead bronze showing the metallic phase and non-metallic phase (magnification $800 \times$ ). 


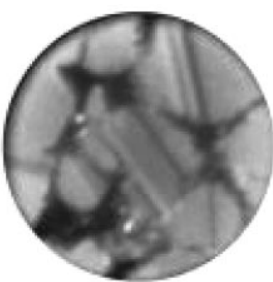

$58 \mathrm{Ni}$

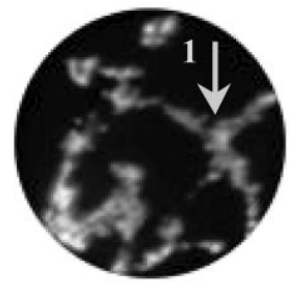

$120 \mathrm{Sn}$

Intensity

$0 \%$

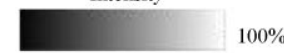

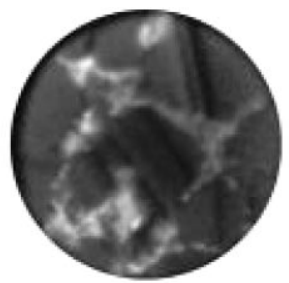

$204 \mathrm{~Pb}$

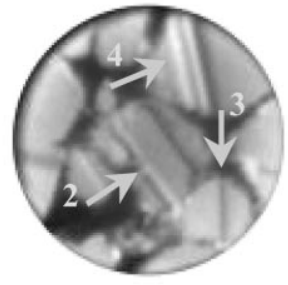

$63 \mathrm{Cu}$

$\varnothing 150 \mu \mathrm{m}$
Fig. 11. SIMS 2D distribution of the elements $\mathrm{Ni}, \mathrm{Pb}, \mathrm{Sn}$ and $\mathrm{Cu}$ in the lead bronze.

from bright- to dark-field. Metal oxides appear in their typical bluish-grey colour using unpolarised light or splendidly colourful under plane-polarised light. Owing to the absence of sulphur in this alloy, all non-metallic inclusions can be regarded as oxides. The dark-grey inclusions comprise of depleted $\mathrm{Cu}$ oxides ( $>80 \%$ ) with $\mathrm{Mn}, \mathrm{Fe}, \mathrm{Ni}, \mathrm{Sb}$ and $\mathrm{Zn}$. Enriched Sn oxides (>70\%) and elements, such as $\mathrm{Cu}, \mathrm{Sb}$ and $\mathrm{Pb}$ form the light-grey inclusions.

Fig. 11 shows 2D SIMS images. Extremely sharp and clearly visible is the texture of a twin line structure marked with arrows 2-4. Elongated Sn powder grains (arrow 1) can be observed, which form the grain boundary in the $\alpha$-phase. However, also part of the Sn is dissolved where $\mathrm{Pb}$ is present. The solubility of $\mathrm{Sn}$ in $\mathrm{Pb}$ at the eutectic temperature $\left(183^{\circ} \mathrm{C}\right)$ is $19 \%$, at room temperature, it is reduced to about $2 \%$. This normally causes considerable precipitations of $\mathrm{Sn}$ - or $\mathrm{Pb}$-rich solutions, which appear as granules or needles within the grains of the Pb-rich solid. That is true for cast alloys but, probably, here for the HIP bronzes too. Such precipitations are also observed although they did not

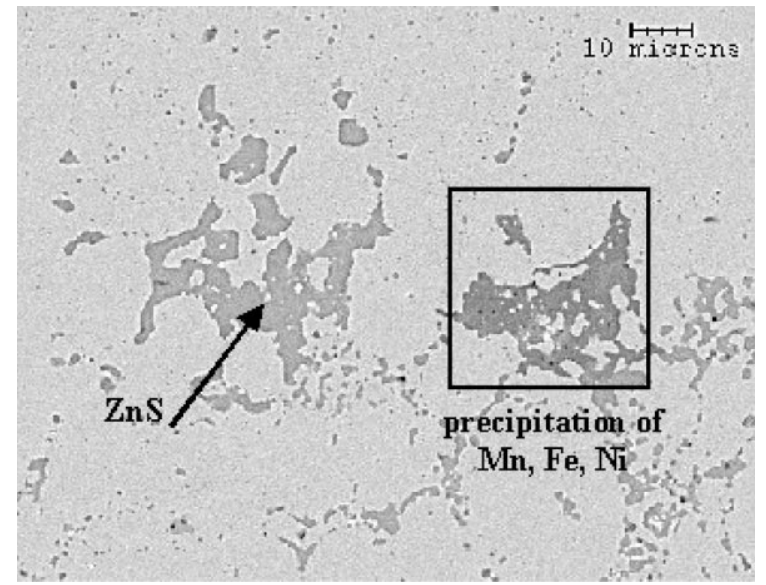

Fig. 12. Backscattered electron image of the brass showing areas of $\mathrm{ZnS}$ and precipitations of $\mathrm{Mn}, \mathrm{Fe}, \mathrm{Ni}$ as sulphides (magnification $950 \times)$.

show the mentioned grains or needles. Important is the agreement of Sn-rich solid solutions in a Pb-rich matrix or vice versa [18]. Ni generates the same ion image as $\mathrm{Cu}$ with somewhat less intensity but this implies a complete dissolution of the element in the $\alpha$-phase.

\subsection{The brass}

For the brass $(\mathrm{Cu}-\mathrm{Zn}$ alloy) sample, little air bubbles are trapped in the metallic phase making it difficult to distinguish them from the small inclusions present. Large blue-grey inclusions are visible under unpolarised light with dimensions of $75 \mu \mathrm{m}$ to maximum sizes of $300 \mu \mathrm{m}$. In these areas, the components $\mathrm{CuO}, \mathrm{CuS}$ and $\mathrm{ZnS}$ are present.

SEM-EDX investigations confirmed the presence of two main phases (Fig. 12): a metallic phase consisting of $\mathrm{Cu}(85 \%), \mathrm{Zn}(11 \%)$ and $\mathrm{Sn}(\sim 3 \%)$, dark-grey inclusions, mainly precipitations of $\mathrm{ZnS}$ with a small percentage of $\mathrm{CuS}(<3 \%)$, bright inclusions as immiscible $\mathrm{Pb}$ and 'black inclusions' $\mathrm{ZnS}$ and $\mathrm{CuS}$ with minor elements, such as Mn and Fe.

Fig. 13 shows SIMS 3D images of minor elements, such as $\mathrm{Fe}, \mathrm{Mn}, \mathrm{Sb}$ and $\mathrm{Ni}$. The presence of $\mathrm{Sb}$ is considered as a contamination, since it was not added deliberately to the alloy. $\mathrm{Ni}$ is quite homogeneously distributed in this analysed area, while $\mathrm{Mn}, \mathrm{Fe}$ and $\mathrm{Sb}$ reveal locally enhanced precipitations. 


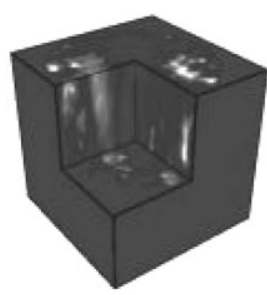

Fe block

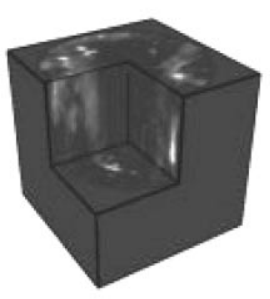

Sb block

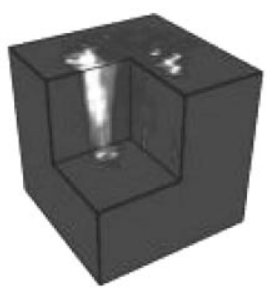

Mn block

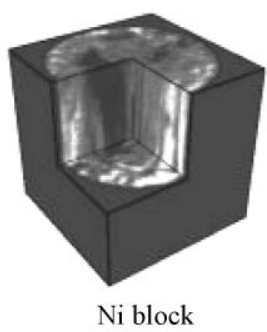

Intensity

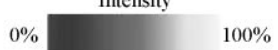

Fig. 13. SIMS 3D distribution of the minor elements $\mathrm{Fe}, \mathrm{Mn}, \mathrm{Ni}$ together with the $\mathrm{Sb}$ contamination. $\mathrm{Fe}$ and $\mathrm{Sb}$ show the same pattern and it can be assumed that the contamination originates from $\mathrm{Fe}$ powder particles.

\section{Conclusions}

Investigations were carried out on a quaternary bronze, an arsenical copper, a tin bronze, a lead bronze and a brass. Table 3 gives an overview of the results. In all five alloys, two main phases can be distinguished, a metallic and a non-metallic phase, the latter being a conglomerate of several types of inclusions. In the case of the quaternary bronze and the brass, the metallic phase consists of $\mathrm{Cu}, \mathrm{Sn}$ and $\mathrm{Zn}$. For the lead bronze and the tin bronze, the major components in the metallic phase are $\mathrm{Cu}$ and $\mathrm{Sn}$. Only in the arsenical copper is the metallic phase formed by $\mathrm{Cu}$ and As.

$\mathrm{Pb}$ is always found as $\mathrm{PbO}$ in separate inclusions because of its inherent characteristic of immiscibility in $\mathrm{Cu}$ matrices. Elements, such as $\mathrm{Mn}, \mathrm{Ni}, \mathrm{Fe}$ and $\mathrm{Sb}$ are found either in small spots or in conglomerates together with the main components. Inclusions of metal oxides are present in all bronze alloys due to the oxidation of the metal powder before or during the HIPing process. Furthermore, in compositions where $S$ was added, combinations of $\mathrm{S}$ with the major and minor elements can be determined.

Quantitative results obtained by SEM-EDX are restricted by the heterogeneity of the samples, by the fact that some interference in the X-ray spectra occurred, and that most of the minor components were close to the detection limit of the instrument.

The investigations carried out within the IMMACO Project have shown that the powder metallurgy method, in which metal powders were blended cold and subsequently HIP resulted in alloys with a certain heterogeneity. Therefore, the minimum analysed area for which the certified values and uncertainties are valid is a spot of diameter $5 \mathrm{~mm}$. Microstructural

Table 3

Overview the two main phases in the different copper alloys

\begin{tabular}{|c|c|c|c|c|}
\hline \multirow[t]{2}{*}{ Alloy } & \multicolumn{2}{|c|}{ Metallic phase } & \multicolumn{2}{|l|}{ Non-metallic phase } \\
\hline & $\alpha$-Phase & Bright inclusion & Dark-grey inclusion & Black inclusion \\
\hline $\begin{array}{l}\text { Quaternary } \\
\text { bronze }\end{array}$ & $\begin{array}{l}\mathrm{Cu} / \mathrm{Sn} \\
\mathrm{Zn}(\sim 3 \%)\end{array}$ & $\begin{array}{l}\text { Immiscible } \mathrm{PbO} \\
(>96 \%)\end{array}$ & $\mathrm{ZnS} / \mathrm{CuS}$ & $\begin{array}{l}\mathrm{ZnS}, \mathrm{CuS}, \mathrm{SnS} ; \mathrm{As}_{2} \mathrm{~S}_{3}, \\
\mathrm{FeS}, \mathrm{NiS}, \mathrm{MnS} \text { and } \mathrm{SbS}\end{array}$ \\
\hline $\begin{array}{c}\text { Arsenical } \\
\text { bronze }\end{array}$ & $\mathrm{Cu} / \mathrm{As}$ & $\begin{array}{l}\mathrm{Sn}(>95 \%) \\
\mathrm{Cu}(>2 \%) \\
\mathrm{As}(\sim 1.4 \%)\end{array}$ & $\mathrm{CuS}$ & $\mathrm{CuS}, \mathrm{As}_{2} \mathrm{~S}_{3}, \mathrm{MnS}, \mathrm{NiS}, \mathrm{SbS}$ \\
\hline Tin bronze & $\begin{array}{l}\mathrm{Cu} / \mathrm{Sn} ; \\
\mathrm{Sb}(<1 \%)\end{array}$ & $\begin{array}{l}\text { Sn-rich }(55 \%) \\
\mathrm{Cu}(40 \%) ; \mathrm{Pb}(>3 \%)\end{array}$ & $\begin{array}{l}\mathrm{Sn} / \mathrm{Mn}(>30 \%) \\
\mathrm{FeS}, \mathrm{ZnS}\end{array}$ & $\mathrm{CuS}, \mathrm{MnS}, \mathrm{FeS}, \mathrm{NiS}, \mathrm{ZnS} ; \mathrm{SbS}$ \\
\hline Lead bronze & $\mathrm{Cu} / \mathrm{Sn}$ & Immiscible $\mathrm{Pb}(>30 \%)$ & $\begin{array}{l}\mathrm{Cu}, \mathrm{Sn} ; \mathrm{Mn}, \mathrm{Fe} \\
\mathrm{Ni}, \mathrm{Sb} \text { and } \mathrm{Zn}\end{array}$ & $(\mathrm{Sn} \text {-rich }>70 \% ; \mathrm{Cu}, \mathrm{Pb} \text { and } \mathrm{Sb})^{\mathrm{a}}$ \\
\hline Brass & $\begin{array}{l}\mathrm{Cu} / \mathrm{Zn} \\
\mathrm{Sn}(\sim 3 \%)\end{array}$ & Immiscible $\mathrm{Pb}(>90 \%)$ & $\mathrm{ZnS} / \mathrm{CuS}$ & $\begin{array}{l}\mathrm{ZnS}, \mathrm{MnS}, \mathrm{Fe}_{2} \mathrm{~S}_{3} ; \mathrm{CuS} \text { and } \\
\mathrm{NiS}(\sim 3 \%)\end{array}$ \\
\hline
\end{tabular}

${ }^{\mathrm{a}}$ Appeared as light-grey inclusions. 
heterogeneities are likely to have an increasingly significant influence on the element mass fractions determined if smaller spot size are used. The reference material should not be used for the calibration of micro-XRF equipment (with spot sizes similar to that of the alloy grain sizes).

\section{Acknowledgements}

The European Commission, DG XII, is gratefully acknowledged for financing the project SMT4-CT962055 "IMMACO”. A.A. is indebted to FWO, Belgium.

\section{References}

[1] R. Widmer, P. Price, Porous Castings? HIPing Might be Your Answer Bronzes, Industrial Materials Technology, Andover, MA, 1982.

[2] C. Ingelbrecht, A. Adriaens, E. Maier, Certification of Arsenic, Lead, Zinc and Tin (Mass Fractions) in Five Copper Alloys, BCR 691, Report EUR 19778/1, 2001.

[3] Proposal for the Standards and Measurements and Testing Program, 4th framework 1994-1998, The European Commission, DG XII, SMT4-CT96-2055 IMMACO.

[4] Guide for Good Analytical Practice, Report EUR 19778-2, 2001.

[5] D. Simpson, W.G. Simpson, Application of Light Microscopy in Analysis, Royal Society of Chemistry, London, 1988, pp. 36-47.

[6] H. Hutter, P. Wilhartitz, M. Grasserbauer, Topochemical characterization of materials using 3D SIMS, Fresenius J. Anal. Chem. 346 (1993) 66-68.
[7] F. Michiels, W. Vanderhoolst, P. van Espen, F. Adams, Acquisition and quantification of ion images with a camera-based detection system and classical quantification algorithms, Am. Soc. Mass Spectrom. 1 (1990) 37-52.

[8] Reichert MeF3 Manual, REICHERT, Vienna, 1985.

[9] Olympus SZX Manual, OLYMPUS Optical Corporation, Germany, 1998.

[10] P. Van Espen, H. Nullens, F. Adams, A computer analysis of X-ray fluorescence spectra, Nucl. Instrum. Meth. 142 (1977) 243-250.

[11] B. Vekemans, K. Jannsens, K. Janssens, L. Vincze, F. Adams, P. Van Espen, Analysis of X-ray spectra by iterative least squares (AXIL): new developments, X-ray Spectrom. 23 (1994) 278-285.

[12] F. He, A generalized approach to quantitative energy-dispersive X-ray fluorescence analysis using fundamental parameters, Ph.D. thesis, Antwerp, 1991.

[13] K. Piplits, W. Tomischko, G. Stingeder, H. Hutter, A new control unit for the CAMECA IMS3f, in: A. Benninghoven, et al. (Eds.), Proceedings of the SIMS VIII, Wiley, Chichester, 1992, pp. 199-202.

[14] K. Piplits, W. Tomischko, Ch. Brunner, H. Hutter, A novel scanning generator for the CAMECA IMS3f, in: A. Benninghoven, et al. (Eds.), Proceedings of the SIMS X, Wiley, Chichester, 1995, pp. 1007-1010.

[15] H. Hutter, P. Wilhartitz, M. Grasserbauer, Topochemical characterization of materials using 3D SIMS, Fresenius J. Anal. Chem. 346 (1993) 66-68.

[16] T. Stubbins, H. Hutter, Combining multispectral image information using color, Anal. Chem. 72 (7) (2000) 282-289.

[17] F. Munnik, K.A. Sjöland, G. Vittiglio, C. Ingelbrecht, U. Wätjen, Nuclear microprobe study of metal segregation in quaternary bronze, Nucl. Instrum. Meth. B 158 (1999) 281286.

[18] W. Hoffmann, Lead and Lead Alloys, 2nd Edition, Springer, Berlin, Germany, 1970. 